\title{
DEROTATION OSTEOTOMY IN THE MANAGEMENT OF CONGENITAL DISLOCATION OF THE HIP
}

\author{
N. J. BLOCKEY
}

\author{
From the Royal Hospital for Sick Children, Glasgow
}

\begin{abstract}
From 1956 to 1965, congenital dislocation of the hip was treated in a standard manner in 191 cases. Reduction and plaster immobilisation was followed by a period in a Batchelor type plaster in full medial rotation. Femoral neck anteversion was then corrected by derotation osteotomy. In 95 children 117 hips were treated in this way and have been reviewed annually for 18 to 27 years. In 1983 they were assessed; there were 101 hips with good clinical results; radiologically, on a modified Severin scale, 62 were good, 39 were fair and 16 were poor.

Derotation osteotomy proved to be the stimulus for growth of the acetabular roof in most cases; its safety, ease of performance and predictability suggest that it is superior to other methods of correcting the dysplasia.
\end{abstract}

In the late 1950 s a policy for the management of congenital dislocation of the hip in children from one to four years old was evolved in our unit. This policy was strongly influenced by the concepts of Somerville and Scott (1957). Some of these ideas were later abandoned because of various problems; thus, in our hands frame reduction proved time consuming and inaccurate, arthrography was misleading, limited excision of soft tissue by limbectomy was inadequate and 14 weeks of treatment seemed too short.

Nevertheless, 31 open reductions for typical congenital dislocation in children aged between 18 months and 4 years confirmed the presence of marked anteversion of the femoral neck in all cases. This finding convinced the writer that Somerville was essentially correct and that, after closed or open reduction, upper femoral derotation was the correct treatment in this age group.

In the years from 1956 to 1965,191 hips with typical congenital dislocation were treated. A number are excluded from this review: some had treatment which differed from the programme described, some had incomplete follow-up and some had inadequate records.

\section{PATIENTS AND METHODS}

A total of 117 hips in 95 children were managed by a standard treatment programme which is described later; all of these were reviewed in 1983 . There were 15 boys and 80 girls. Twenty-two children had bilateral dislocations. Cases of muscle disease and of spina bifida were excluded.

N. J. Blockey, FRCS, MChOrth, Consultant Orthopaedic Surgeon Department of Orthopaedics, Royal Hospital for Sick Children, Yorkhill, Glasgow G3 8SJ, Scotland.

(C) 1984 British Editorial Society of Bone and Joint Surgery $0301-620 \times / 84 / 4117 \$ 2.00$
Arthrography was used only in the early cases; dislocation was distinguished from subluxation by the superolateral displacement of the femoral head in a plain radiograph taken supine and by the presence of the characteristic clinical signs.

Policy. All children were under the care of the author who, from his study of previous series, had concluded that the essential steps of management should be: first, accurate deep reduction held for three months in plaster; secondly, a Batchelor type plaster in medial rotation (Batchelor 1951), allowing movement of the abducted hip; thirdly, operative correction of excessive anteversion; and finally a further prolonged period of immobilisation in abduction. Operations on the acetabulum would not be used.

Treatment. Under general anaesthesia the dislocated hip was manipulated by traction in the flexed position, followed by abduction with pressure over the greater trochanter. If the sensation of full reduction was felt, subcutaneous adductor tenotomy was performed and a radiograph was taken. If this film was satisfactory the legs and pelvis were placed in plaster with the hips flexed a little more than $90^{\circ}$ and in $70^{\circ}$ to $80^{\circ}$ of abduction. This plaster was retained for three months and then changed for another, holding the hips in abduction and neutral rotation for a further month. Four months after reduction the affected leg was rolled into full medial rotation and a Batchelor plaster applied. This stayed on for three months.

At seven months from reduction a $90^{\circ}$ derotation osteotomy of the femur was performed and fixed with a vitallium plate and screws; a plaster spica was worn for six weeks until the osteotomy had united.

The stitches were then removed and a broomstick plaster in abduction applied and worn for six weeks. Then a radiograph was taken to show the direction of the 
femoral neck and the state of ossification of the acetabular roof. Treatment ceased 10 months after reduction of the dislocation. Even if there was apparent inadequacy of the bony roof of the acetabulum, the temptation to intervene at this stage was resisted, and the child was allowed to get up, walk and lead a normal life. The plates and screws were removed if there was a definite reason for doing so; this occurred in 23 hips.

Open reduction. If at the first manipulation either the sensation of reduction was lacking, or the radiographic reduction was unconvincing, then a formal open reduction was performed. Somerville's operation of limbectomy was abandoned because in two cases the hip redislocated.

At operation the ligamentum teres was excised, the psoas tendon either retracted or divided and the contents of the true acetabulum cleared by sharp dissection. The femoral head was then reduced into the prepared socket by downward traction and full medial rotation so that its articular cartilage disappeared completely from view. This manoeuvre closed the capsular incision without need for suture and brought the trochanter to a lateral position. The rectus femoris was then repaired. No attempt was made to alter or to stimulate the roof of the acetabulum. The muscles were reattached to the iliac crest, the wound was closed and a plaster spica applied to hold the leg in full medial rotation.

Of the 117 hips in this series, 27 required open reduction. Three months after open reduction a $90^{\circ}$ derotation osteotomy of the upper femur was carried out; thereafter the management was the same as that described after closed reduction.

Review. No additional treatment was given, because it seemed important to know the results of the primary treatment, unaltered by subsequent measures. All the children were followed to skeletal maturity with regular clinical assessments and annual radiographs. The results are presented from 18 to 27 years after the initial reduction, and have been assessed using a modification of Severin's (1941) criteria.

Comparison with the Oxford series. Gibson and Benson (1982) published the results obtained in Oxford, where of course Somerville's concepts were used. They reviewed 182 hips at maturity. An arthrogram had been used to detect an obstructing limbus. None was present in 35 hips, which were treated for six weeks by plaster in medial rotation; derotation osteotomy was then performed. The limbus seen in 147 hips in 121 patients was excised before the derotation osteotomy; these 147 hips were treated at one to three years of age, and were assessed clinically and radiologically at maturity using a variation of the grades of Severin (1941).

However, only 68 of these hips had been managed exclusively as described by Somerville in 1957; the other 79 had additional operations during childhood. Twentyfive had varus angulation as well as derotation at their osteotomy; 14 of these were in radiological Grades I and
II at maturity. Many of the 79 hips showed signs of progressive subluxation and 41 of these were treated later by varus osteotomy; four had a third femoral osteotomy and a further 13 had a late pelvic osteotomy. Less than half of the hips were improved by these later procedures.

The published results of the whole series showed $74 \%$ clinically excellent but only $47 \%$ in radiological Grade I or II, with $44 \%$ showing evidence of degenerative change. These results followed a variety of managements but shed nolight on the possible incidence of degenerative changes if fewer late operations had been performed. The high incidence of progressive subluxation seems likely to have been due to the short total duration of treatment, only 10 to 14 weeks. It could be argued that the 79 hips which had additional operations would have been worse without these additions, but there can be no proof of this.

The results of treatment in the 117 hips reported in this present paper, can be compared with the results of those 68 hips in the Oxford series which had only one operation. The important differences in management are that the 117 had closed or full scale open reductions and 10 months treatment, while the 68 had the limited procedure of limbectomy and only 14 weeks treatment. An analysis of both groups together gives 185 hips assessed in early adult life, all after derotation osteotomy. A comparison of the two groups should help to show whether Somerville was basically correct, or whether Salter's (1961) view that acetabular roof development is unreliable in this age group should prevail and that innominate osteotomy should be the treatment of choice.

\section{RESULTS}

All 95 patients, with 117 hips treated from 1956 to 1965 , are fully active and mobile. None was made worse by treatment and there were no nerve lesions, deep infections, or other serious complications. There were no redislocations. The classification used by Gibson and Benson (1982), as modified from Severin (1941), has been

Table I. Method of grading results

\begin{tabular}{|lll|}
\hline Result & Assessment & $\begin{array}{l}\text { Severin } \\
\text { Grade }\end{array}$ \\
\hline Good & $\begin{array}{l}\text { Normal hips, no pain, no limp, full } \\
\text { function. CE angle 25 or greater. }\end{array}$ & I \\
& $\begin{array}{l}\text { Mild deformity of head or neck but hip } \\
\text { deeply and concentrically reduced. } \\
\text { Shenton's line normal. Function, } \\
\text { movement and CE angle as in Grade I. }\end{array}$ & II \\
Fair & $\begin{array}{l}\text { Dysplastic hip without subluxation. } \\
\text { Shenton's line normal but incomplete } \\
\text { head coverage. CE angle less than 25 }\end{array}$ & III \\
Slight shortening or slight restriction of \\
activity. \\
Poor \\
$\begin{array}{l}\text { Occasional pain. Noticeable limp. } \\
\text { Moderate restriction of endurance. } \\
\text { Broken Shenton's line. } \\
\text { Articular sclerosis or lack of concentricity } \\
\text { or early OA changes. }\end{array}$ & V IV \\
\hline
\end{tabular}




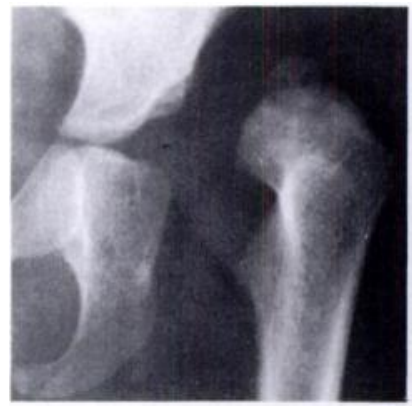

Fig. 1

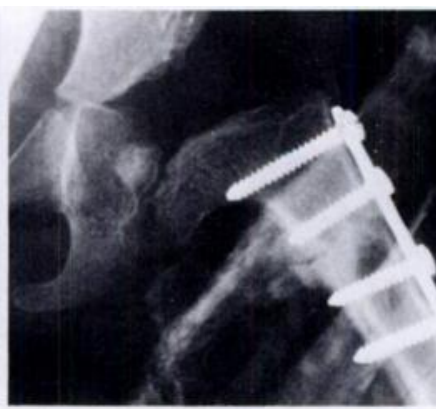

Fig. 2

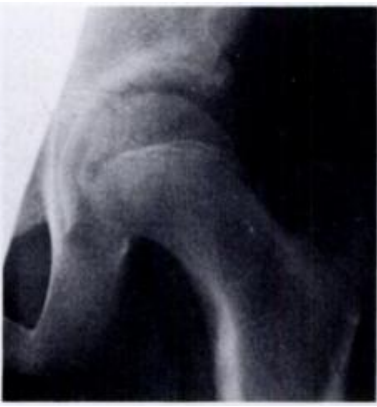

Fig. 3

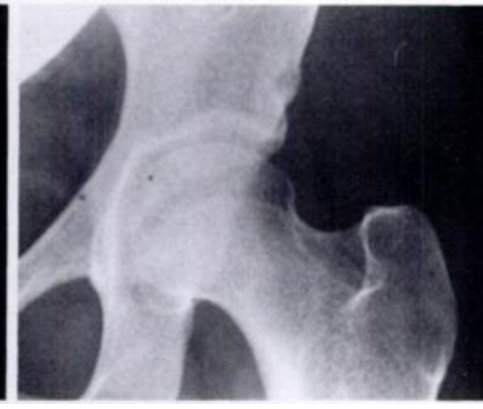

Fig. 4

Radiographs showing a good result in a favourable hip. Figure 1-Left hip of an 18 month old girl. Figure 2 - The same hip on completion of 10 months of treatment. Figure 3-Nine years later. Figure 4--The same hip when the patient was 22 years old.

applied. Concentric rings were used on the final radiograph to determine the CE angle. The hips were graded "good", "fair" and "poor" combining Severin's grades as shown in Table I.

At follow-up in 1983, 101 of the 117 hips were clinically satisfactory, and the patients were leading normal lives without pain or disability. On Severin's criteria 62 hips were in Grade I or Grade II and were recorded as good results. Fifteen hips with good radiographs in childhood failed to achieve a CE angle of $25^{\circ}$ as adults and are therefore in Severin Grade III. Another

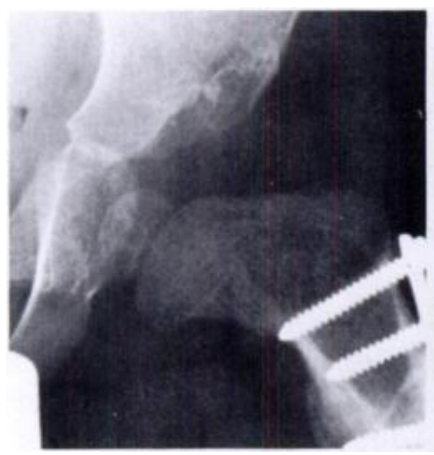

Fig. 5

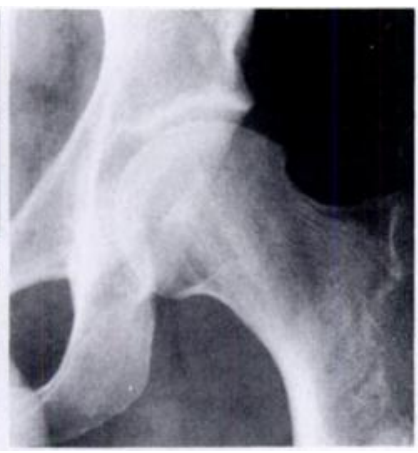

Fig. 6
Radiographs showing a good result in less favourable conditions. Figure 5 - Left hip of a boy after open reduction at the age of 2 years and 10 months, followed by standard treatment including derotation osteotomy. Figure 6 -Result of this treatment 20 years later.
24 are in this grade because of other minor radiographic imperfections giving a total of 39 in Grade III, recorded in this paper as fair results. Sixteen hips were in Severin Grades IV and V, and are considered to show poor results.

Good results. There were 62 good results from 117 hips at 18 to 27 years after reduction. A typical case of unilateral dislocation of the left hip in a girl aged 18 months is shown from the time of her closed reduction to the age of 20 years (Figs 1 to 4). The correction of anteversion, the low placement of the head and the subsequent development of the acetabular roof, have resulted in a normal hip.

This group includes some children with less favourable early appearances. In a boy aged two years and 10 months the radiograph six months after open reduction shows lack of acetabular growth (Fig. 5); despite this, full activities were allowed and 20 years later (Fig. 6) the hip was graded good.

A girl aged as much as three years and five months at reduction (Fig. 7), obtained a good hip by the treatment described; although growth of the acetabular roof on the post-treatment radiograph (Fig. 8) was poor, no further operation was performed. Figures 9 and 10 show development of this hip to the age of 19 years.

These cases suggest that concentric reduction followed by derotation osteotomy can stimulate development of the acetabular roof without the need for varus at

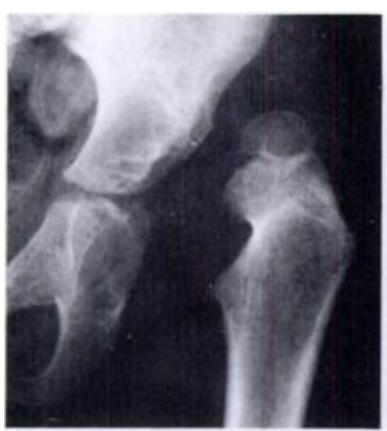

Fig. 7

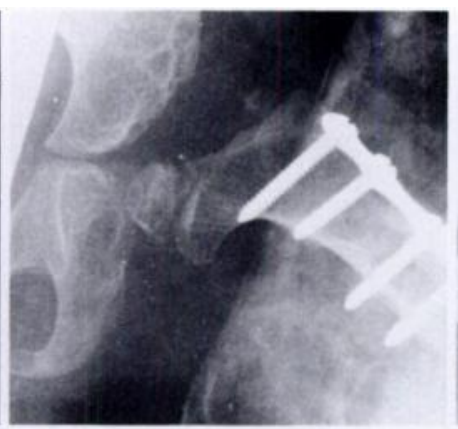

Fig. 8

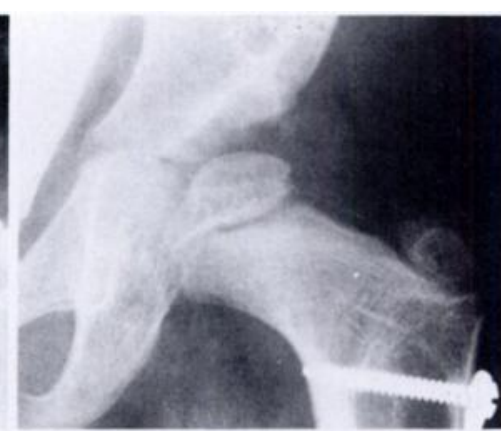

Fig. 9

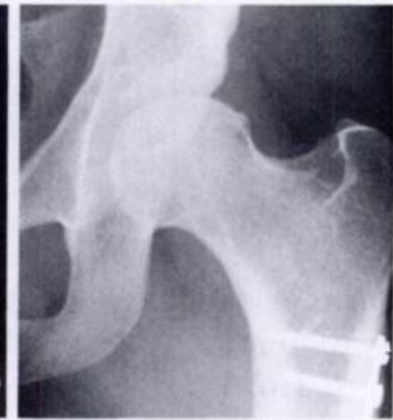

Fig. 10

Radiographs showing a good acetabular response after late diagnosis and reduction. Figure 7 - Left hip of a girl aged 3 years and 5 months. Figure 8 - Ten months after reduction and standard management. Figure 9 - Three years after reduction, at the age of $6 \frac{1}{2}$ years. Figure 10 - The same hip, when the patient was 19 years old. 
the osteotomy and without any operation on or above the acetabulum.

Fair results. Radiologically 39 hips were graded fair. Clinically these hips were good, though six have coxa vara and slight shortening. All have an unbroken Shenton's line but are not in the good grade because of minor radiological abnormalities. The most common, seen in 15 cases, was incomplete coverage of the head (Fig. 11). Four showed slight sclerosis of the acetabular roof (Fig. 12).

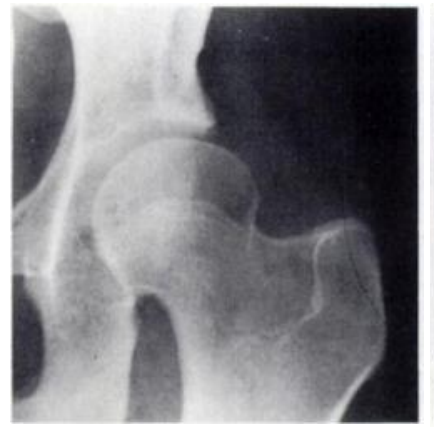

Fig. 11

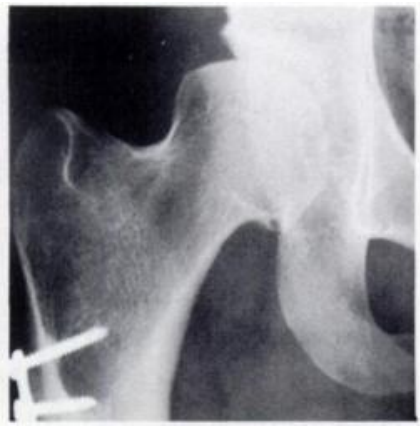

Fig. 12
Figure 11-Incomplete cover of the head of the femur in the left hip of a woman aged 23 years. CE angle $20^{\circ}$, grade fair. Figure $12-$ Radiograph showing sclerosis in the right hip of a woman aged 25 years. CE angle $15^{\circ}$, sclerosis of lip of acetabulum, grade fair.

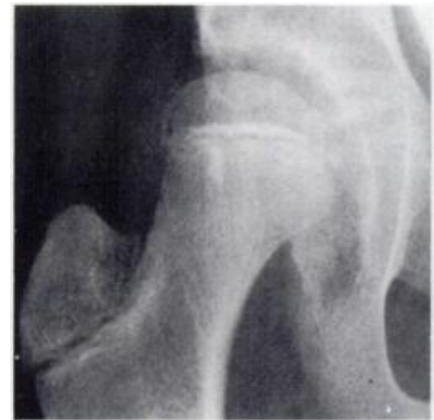

Fig. 13

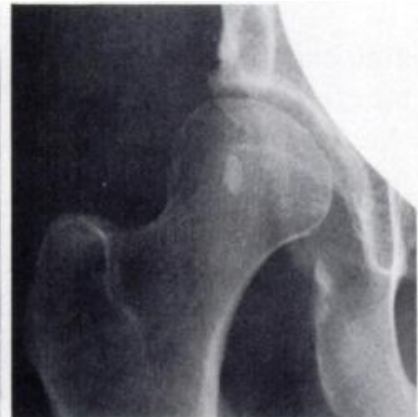

Fig. 14
Radiographs to show "saucering", that is, increase in superoinferior diameter of the acetabulum, but with no deterioration after 13 years. Figure 13-Right hip of a girl aged 11 years, nine years after reduction, showing marked saucering. Figure 14-The same hip, when the patient was aged 24 years. Grade fair.
Eleven hips showed "saucering", that is, a considerable increase of the superoinferior diameter of the acetabulum, usually with some coxa valga; in nine of these there was, surprisingly, $1 \mathrm{~cm}$ of leg lengthening. Five of these hips had had an open reduction. This "stretching" of the acetabulum does not necessarily make the prognosis worse (Figs 13 and 14).

Poor results. Any degree of subluxation relegates the result to this group, which contained 16 hips in this series. Nine of these looked as if they had never been deeply reduced, though seven of these nine had had open reduction. Two of the poor results had other congenital abnormalities; one had a club foot, and the other was mentally retarded. Late loss of articular cartilage was seen in two hips, and two others had coxa vara with distortion of the femoral head. One hip showed coxa valga with pressure sclerosis.

Using Gibson and Benson's (1982) criteria for degenerative changes (loss of joint space, sclerosis of the weight-bearing segment, osteophytes and cyst formation) three of the 117 hips show osteoarthritis. The worst case clinically and radiologically is a woman aged 26 who had a closed reduction and the standard management for the series. Her post-treatment radiograph (Fig. 15) at the age of two years showed features usually indicative of a good result; at the age of 12 her hip was normal (Fig. 16), but in her early twenties her hip stiffened and became osteoarthritic (Fig. 17). In the series reported by Gibson and Benson, in which every hip had an open reduction, 18 of 147 hips were found to have similar major arthritic changes. In this present series open reduction was necessary in only $23 \%$ of 117 hips, and only three had disability from osteoarthritis.

The left hip of an active school teacher aged 22 is seen in Figure 18; it is mobile but, like nine similar hips, is graded as a poor result. There has been no proximal migration in the last 10 years; this suggests that a $90^{\circ}$ derotation osteotomy helps to prevent total redislocation.

One result seems inexplicable: a girl with typical congenital dislocation of the right hip at 20 months (Fig. 19) had the standard management and her radiograph after treatment (Fig. 20) is similar to many which went

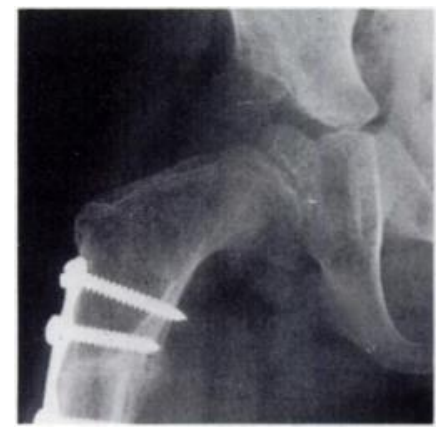

Fig. 15

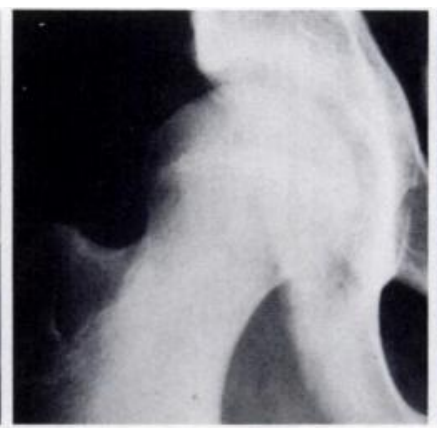

Fig. 16

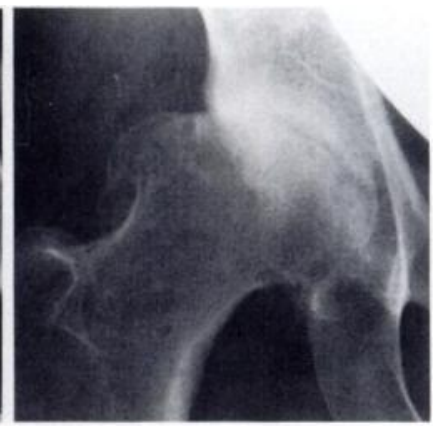

Fig. 17

Radiographs showing late deterioration. Figure 15-Right hip of a girl aged 2 years, at the end of treatment. Figure 16-The same hip 10 years later, shows no disturbing features. Figure 17-At the age of 26 her hip shows loss of articular cartilage and osteoarthritis. 


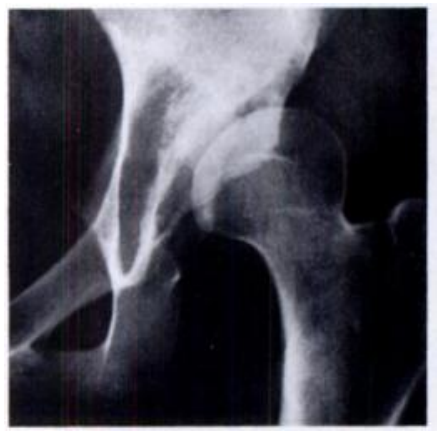

Fig. 18

Radiograph of the left hip of an active school mistress aged 22 years. There has been no proximal redislocation after derotation osteotomy. The patient is mobile and not yet arthritic. Grade poor.

on to be graded good; however, after 19 years, she has subluxation of both hips (Fig. 21). This case suggests that in some patients there is a genetically determined final shape for the acetabulum. The shape remains stubbornly uninfluenced by a deeply placed derotated femoral head, which in most instances provided a good stimulus for the development of acetabular concentricity.

Osteochondritis. The changes of osteochondritis were seen in 16 hips, three of which had been reduced at under

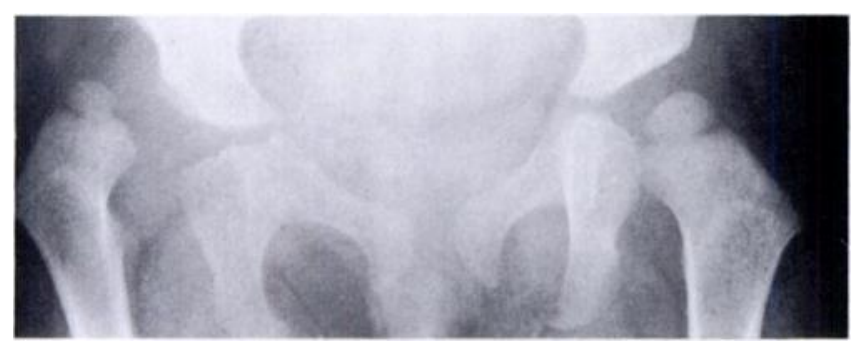

Fig. 19

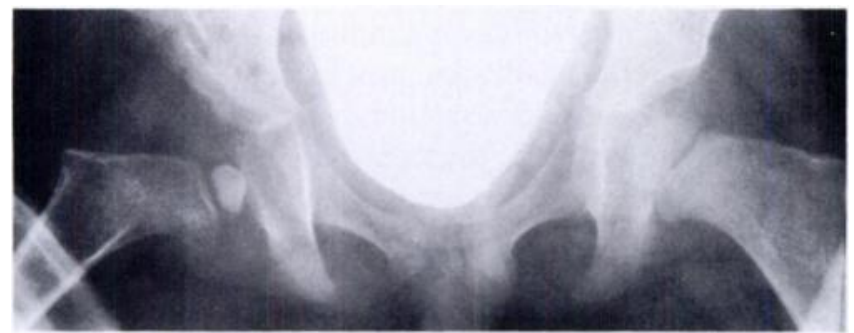

Fig. 20

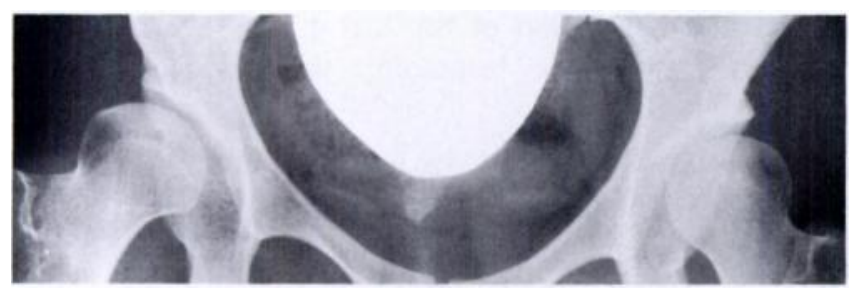

Fig. 21

Radiographs to show "saucering" which could be genetically determined. Figure 19-Both hips of a girl aged 20 months. Congenital dislocation of the right hip was treated in the standard way described in the text. Figure 20-The same hips just before derotation osteotomy of the right femur. Figure 21 -At the age of 22 , her hips show bilateral saucering.
13 months of age. The result in 12 of these hips was fair, but four with more serious deformities of head and neck were graded poor. A $12 \%$ incidence of osteochondritis in this series is significantly higher than the $5.4 \%$ reported in the Oxford series (Gibson and Benson 1982) in which a period of traction preceded reduction of the dislocation.

\section{PROGNOSIS}

Table II relates the end result to the use of closed or open reduction: no significant effect is seen. No satisfactory method of estimating the depth of reduction could be found and measurement of the acetabular angle on the early radiographs was not exact enough to be of value. Gibson and Benson (1982) found good end results in 56\% of cases when the original acetabular angle was less than

Table II. Relationship of result to the method of reduction

\begin{tabular}{|lllll|}
\hline & \multicolumn{4}{c|}{ Grade } \\
\cline { 3 - 5 } Method of reduction & Number of hips & Good & Fair & Poor \\
\hline Open & 27 & 13 & 10 & 4 \\
Closed & 90 & 49 & 29 & 12 \\
Total & 117 & 62 & 39 & 16 \\
\hline
\end{tabular}

$40^{\circ}$, but in only $33 \%$ when this angle was over $50^{\circ}$. The original radiographs of those hips which, in this present series, were eventually graded good showed a variety of acetabular roof angles (Figs 1, 5 and 7); the angles were not measurably better than those of many hips finally graded poor.

When the acetabular roof is sloping it seems particularly important to hold the hip in abduction for far longer than 14 weeks. Study of the radiographs in this present series suggested that, providing abduction was held for a prolonged period, then reconstruction of the acetabular roof, even when its slope was strikingly poor, was not needed.

Table III relates age at reduction with the final result and shows no correlation. This is again at variance with the Oxford series, in which only $31 \%$ were graded good when the original reduction was in the third year of life, while $73 \%$ were good after reduction at 12 months of age.

Table III. Relationship of result to age at reduction

\begin{tabular}{|lccccc|}
\hline & \multicolumn{5}{c}{ Grade } \\
\cline { 5 - 6 } Age at reduction & Children & Hips & Good & Fair & Poor \\
\hline$<13$ months & 5 & 5 & 1 & 3 & 1 \\
$13-24$ months & 60 & 72 & 42 & 22 & 8 \\
$25-36$ months & 23 & 29 & 14 & 10 & 5 \\
$37-48$ months & 7 & 11 & 5 & 4 & 2 \\
Total & 95 & 117 & 62 & 39 & 16 \\
\hline
\end{tabular}




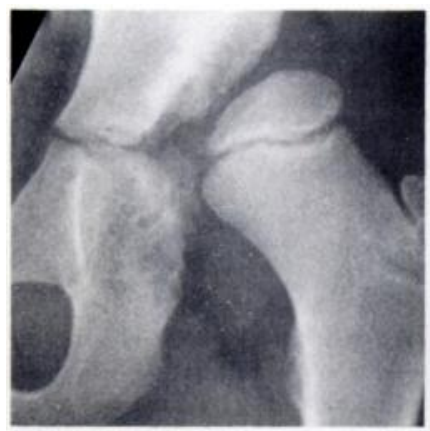

Fig. 22

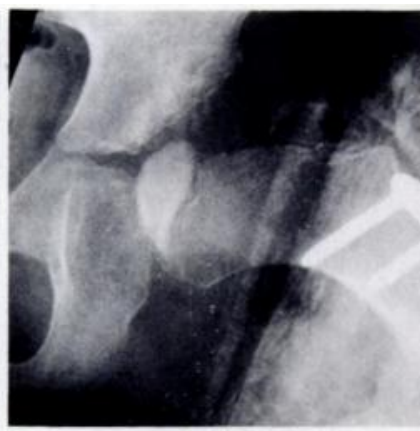

Fig. 23

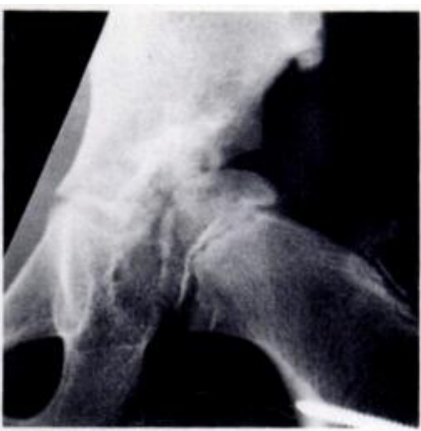

Fig. 24

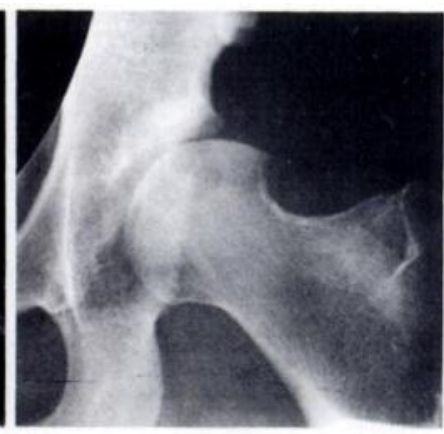

Fig. 25

Radiographs to show the result of late derotation osteotomy. Figure 22-Left hip at the first presentation of a girl aged 6t years. Figure 23-The same hip on completion of treatment. Figure 24-After three years there has been a good acetabular response. Figure 25-The same hip when the patient was 24 years old; she had normal function.

Derotation osteotomy in the older child did not improve the prognosis after the age of eight years, but was used successfully in two children of 6 years. One of these two presented at $6 \frac{1}{2}$ years of age (Fig. 22); she had an open reduction and femoral osteotomy; the hip continued to develop well and at 24 years she had normal function (Figs 23, 24 and 25).

Bilateral dislocation was seen in 22 children; the original displacement was always unequal on the two sides, as was the outcome. In total, 25 of these 44 hips were graded good, 14 were fair and five were poor.

No absolutely reliable factors in prognosis could be found. Deep reduction, low placement of the head in the socket and good fixation of the osteotomy seemed to be important for a good result, though not invariably.

\section{DISCUSSION}

In the Oxford series Gibson and Benson (1982) reported that $28.5 \%$ of 147 hips were in Severin Grade III at follow-up. In this series, $13 \%$ of 117 are in this grade because inadequate head cover gave a CE angle of less than $20^{\circ}$. As yet we cannot know what these hips will be like in middle age. If all these patients develop osteoarthritis after another 20 years, while patients having other methods of treatment do not, then Somerville's concept may need to be shelved. The 40-year results in those graded fair because of coxa valga or acetabular sclerosis can more easily be forecast, but longer term follow-up is necessary. At present $\mathbf{3 8}$ fair hips from this present series and 42 from the Oxford series are functioning painlessly and well in their twenties. They show no osteoarthritis but have some radiological features which cause concern.
Of the 16 hips graded "poor", nine show subluxation, and it seems that reduction, by open operation in seven, was not deep enough. Also associated with inferior results are saucering (increased superoinferior diameter of the acetabulum), and chondrolysis (loss of articular cartilage) which can develop suddenly in later childhood. Gibson and Benson (1982) reported a higher incidence of this type of degeneration, which suggests that operation may be a predisposing factor, although the example shown in Figs 17,18 and 19 followed a closed reduction and is therefore, like saucering, not yet explained.

Conclusions. In all published series the 20-year follow-up results are worse than the short term results; but we are still unable to answer some of the questions posed by this deterioration. It must suffice to report that in this series 101 of 117 hips, and in the Oxford series 109 of 147 hips are clinically excellent or good with the patients in their twenties. Many will need arthroplasty later in life, some for reasons which are not yet apparent. Continued followup is necessary in both series, especially to determine the outcome of the Grade III or fair results.

Derotation osteotomy is simple, is safe, and provides predictably good results in most cases. It has proved effective in typical dislocations; and in some which seemed less favourable; thus a boy of 3 who had an open reduction, and two girls aged $3 \frac{1}{2}$ and $6 \frac{1}{2}$ who both had gross deficiency of the acetabular roof, all have good results in adult life without having been exposed to difficult acetabular surgery; their radiographs have been presented. It would therefore seem unwise to treat typical congenital dislocation of the hip in this age group by primary innominate osteotomy without evidence of superior results.

\section{REFERENCES}

Batchelor JS. Symposium on congenital dislocation of the hip. J Bone Joint Surg [Br] 1951;33-B: 288.

Gibson PH, Benson MKD. Congenital dislocation of the hip: review at maturity of 147 hips treated by excision of the limbus and derotation osteotomy. J Bone Joint Surg [Br] 1982;64-B:169-75.

Salter RB. Innominate osteotomy in the treatment of congenital dislocation and subluxation of the hip. J Bone Joint Surg [Br] 1961:43-B 518-39.

Severin E. Contribution to the knowledge of congenital dislocation of the hip joint: late results of closed reduction and arthrographic studies of recent cases. Acta Chir Scand $1941 ; 84$ :Suppl 63.

Somerville EW, Scott JC. The direct approach to congenital dislocation of the hip. J Bone Joint Surg [Br] 1957:39-B:623-40. 